\title{
Methods of soil organic carbon determination in Brazilian savannah soils
}

\author{
Juliana Hiromi Sato ${ }^{1}$, Cícero Célio de Figueiredo ${ }^{*}$, Robélio Leandro Marchão², Beáta Emöke Madari ${ }^{3}$, Luiz Eduardo Celino \\ Benedito $^{1}$, Jader Galba Busato ${ }^{1}$, Diego Mendes de Souza ${ }^{3}$
}

\author{
'University of Brasília/Faculty of Agronomy and Veterinary \\ Medicine, ICC Sul, Campus Darcy Ribeiro, Asa Norte - \\ 70910-970 - Brasília, DF - Brazil. \\ 2Embrapa Cerrados, BR 020, km 18 - 73310-970 - \\ Planaltina, DF - Brazil. \\ 3Embrapa Rice and Beans, Rod. GO 462, km 12 - 75375- \\ 000 - Santo Antônio do Goiás, GO - Brazil. \\ *Corresponding author <cicerocf@unb.br> \\ Edited by: Silvia del Carmen Imhoff
}

Received September 18, 2013

Accepted March 16, 2014

\begin{abstract}
Several methods exist for determining soil organic carbon, and each one has its own advantages and limitations. Consequently, a comparison of the experimental results obtained when these methods are employed is hampered, causing problems in the comparison of carbon stocks in soils. This study aimed at evaluating the analytical procedures used in the determination of carbon and their relationships with soil mineralogy and texture. Wet combustion methods, including Walkley-Black, Mebius and Colorimetric determination as well as dry combustion methods, such as Elemental and Gravimetric Analysis were used. Quantitative textural and mineralogical (kaolinite, goethite and gibbsite) analyses were also carried out. The wet digestion methods underestimated the concentration of organic carbon, while the gravimetric method overestimated. Soil mineralogy interfered with the determination of carbon, with emphasis on the gravimetric method that was greatly influenced by gibbsite.
\end{abstract}

Keywords: soil organic matter, wet combustion, dry combustion

\section{Introduction}

The Brazilian savannah has been widely used for agricultural production, and the incorporation of natural areas for agricultural activities has resulted in the loss of soil organic matter and consequent emission of greenhouse gases (Resck et al., 2008). Recently, the Brazilian government has made considerable efforts to reduce the impact of the different sectors of its economy on climate change in the medium and long-term, through public policies. To verify the fulfillment of the goals projected in the Low Carbon Emission in Agriculture - ABC Plan, it is necessary to consolidate basic methodology for the measurement of soil $\mathrm{C}$ concentration.

Several methods are used to determine C in soils, from those based on wet oxidation, such as classic dichromatometry, to autoanalyzers constructed for this purpose, such as CHNS/O (Nelson and Sommers, 1996). Wet combustion methods are more accessible, despite the use of toxic reagents (Pimentel et al., 2006). The advent of automated devices has brought advances in analysis. Elemental analysis (CHNS/O) allows for rapid and reliable determinations by dry combustion; however, the cost of each determination is higher than the cost of wet combustion methods (Segnini et al., 2008). Due to low sample throughput and difficulty in automation, gravimetric dry combustion is rarely used in routine laboratories (Miyazawa et al., 2000). However, it is a method that does not use toxic reagents that would be ideal in view of current environmental concerns.

Each method has its own advantages and limitations and has different relation with soil texture and mineralogy (Zinn et al., 2007). Furthermore, the recovery efficiency of $\mathrm{C}$ by different methods depends on the type of substrate that comprises the organic matter (Conyers et al., 2011; Carmo and Silva, 2012) hence, there is still no concensus on considering one ideal method as stan- dard, making the comparison of experimental results difficult, and causing problems in the evaluation of soil $\mathrm{C}$ stocks.

The expansion of conservation tillage systems for low $\mathrm{C}$ emission increases the need to monitor changes in soil $\mathrm{C}$, and therefore the need to standardize procedures through the comparison between the different methods. Therefore, this study aimed at evaluating and comparing methods employed for the determination of carbon in savannah soils varying in texture and mineralogy.

\section{Materials and Methods}

\section{Soil Samples}

Fifty-four (54) soil samples were collected at 0-20 $\mathrm{cm}$ in areas representing sub-regions, soil types and the history of use and management in the Brazilian savannah (Cerrado) (Figure 1). The total number of samples was composed of two groups, 27 samples of native areas and 27 from agricultural areas. The samples were obtained randomly, according to geographic coordinates specified so that in some cases native and agricultural areas did not correspond to the same soil. Agricultural areas had different historical usages, some subjected to no-tillage and others to conventional systems. Textural analysis was performed using the pipette method (Sheldrick and Wang, 1993). Soil organic carbon was determined by five methods. For all methods three replicates were used.

\section{Determination of soil organic carbon}

Walkley and Black method (Walkely and Black, 1934): The soil, ground up so as to pass through a 0.5 $\mathrm{mm}$ mesh sieve, was placed in a $500 \mathrm{~mL}$ Erlenmeyer flask. The amount of soil used in the determination was calculated based on initial information on the C concen- 


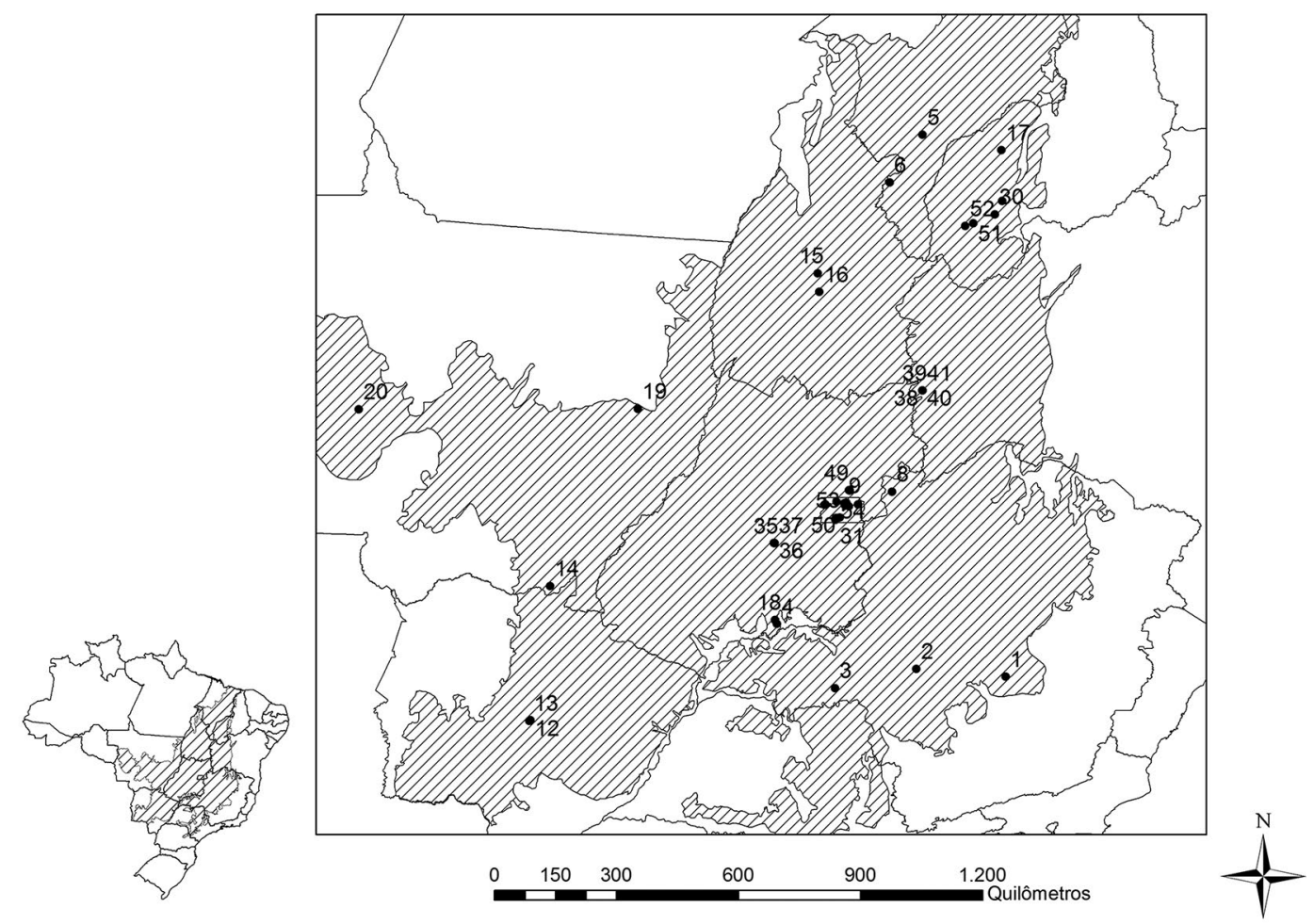

Figure 1 - Distribution of the sampling points in the Brazilian savannah region.

tration in the soil and ranged from 0.1 to $0.5 \mathrm{~g}$. Ten milliliters of 0.167 potassium dichromate $\left(\mathrm{K}_{2} \mathrm{Cr}_{2} \mathrm{O}_{7}\right)$ and 20 $\mathrm{mL}$ of concentrated sulfuric acid $\left(\mathrm{H}_{2} \mathrm{SO}_{4}\right)$ were added to the soil while stirring it to ensure good mixing of the soil with the reagents. After a 30-min rest $200 \mathrm{~mL}$ of distilled water, $10 \mathrm{~mL}$ of concentrated $\mathrm{H}_{3} \mathrm{PO}_{4}$ and $1 \mathrm{~mL}$ of 0.16 $\%$ diphenylamine were added. The excess dichromate that was not reduced in the reaction was determined by volumetric titration using ammonium ferrous sulfate $\left.\left[\mathrm{Fe}\left(\mathrm{NH}_{4}\right)_{2}\left(\mathrm{SO}_{4}\right)_{2} 6 \mathrm{H}_{2} \mathrm{O}\right)\right]$ (Mohr's salt).

Mebius method (Mebius, 1960): The same procedure was followed as in the case of the Walkley and Black, but the digestion mixture of potassium dichromate with sulfuric acid was submitted to external heating on an electric plate at $100{ }^{\circ} \mathrm{C}$ for $30 \mathrm{~min}$ under reflux. Then phosphoric acid and diphenylamine were added similarly to the Walkley and Black method and the excess dichromate was titrated with ammonium ferrous sulfate.

Colorimetric method (Nelson and Sommers, 1996): A thousand milligrams $(1,000 \mathrm{mg})$ of soil was ground up so as to pass through a sieve of $0.5 \mathrm{~mm}$ mesh and placed in a $250 \mathrm{~mL}$ Erlenmeyer flask. Ten milliliters $(10 \mathrm{~mL})$ of 0.667 sodium dichromate mixed with $5 \mathrm{M}$ sulfuric acid were added and the suspension was stirred in a circular motion using a horizontal shaker for 10 minutes at $180 \mathrm{rpm}$. After the shaking, the suspension remained undisturbed for one hour and then $50 \mathrm{~mL}$ distilled water was added. The supernatant was collected and the absorption of the solution at $660 \mathrm{~nm}$ was measured using a B220 photoelectric colorimeter (Micronal, USA). The calibration curve was prepared using different concentrations $\left(0.00,0.05,0.15,0.30\right.$ and $\left.0.50 \mathrm{~g} \mathrm{~L}^{-1}\right)$ of glucose in solution.

Gravimetric method or loss-on-ignition: Four grams $(4 \mathrm{~g})$ of soil that passed through a sieve of $2 \mathrm{~mm}$ mesh was further dried at $105{ }^{\circ} \mathrm{C}$. Preliminary tests were carried out with samples that passed sieves of 2.0 and $0.5 \mathrm{~mm}$ mesh. After checking that there were no differences between SOC levels obtained for each mesh, the one of $2.0 \mathrm{~mm}$ was selected due to practical reasons. The samples were subjected to calcination for $5 \mathrm{~h}$ at 300 ${ }^{\circ} \mathrm{C}$ (Miyazawa et al., 2000). Subsequently, the samples were weighed and the difference between the initial and final mass corresponded to the organic matter of the soil.

Elemental Analysis (CNHS/O): Thirty milligrams (30 $\mathrm{mg}$ ) of soil ground up so as to pass through a $0.149 \mathrm{~mm}$ mesh sieve were placed in a tin capsule and combusted at $975^{\circ} \mathrm{C}$. An automatic analyzer Model PE 2400 Series II CHNS/O (Perkin Elmer, Norwalk, CT, USA) equipped with a thermoconductivity detector was used. This method is considered the standard method for determination of total soil carbon. 


\section{Soil mineralogy analysis}

The determination of the amounts of gibbsite, goethite and kaolinite was carried out by thermogravimetry. The thermograms were obtained with the use of TGA 50 equipment (Shimadzu, Japan). The samples were placed in alumina cells, with a capacity of $20 \mathrm{mg}$, under nitrogen at a constant flow. The temperature range of the analysis was between room temperature and $800^{\circ} \mathrm{C}$ at a heating rate of $10^{\circ} \mathrm{C}$ per min.

\section{Statistical Analysis}

Analyses were performed using the XLSTAT 2011 software (Addinsoft, Statistical Analysis System, 2011). Data were fitted by linear regression using the $C$ values obtained by elemental analysis as independent variables.

\section{Results and Discussion}

\section{The carbon concentration determined by the meth-} ods

The highest levels of carbon were obtained by elemental analysis (Table 1), regardless of the soil type or form of land use. This analytical method has been widely used, all over the world, in studies for determining total soil $\mathrm{C}$, since at the utilized combustion temperature (generally above $900{ }^{\circ} \mathrm{C}$ ) the whole sample is entirely oxidized allowing for measurement of both organic and inorganic C. Thus, this method is considered as a benchmark for total soil C analysis (McCarty et al., 2010). The average value for soil organic carbon (SOC) measured by this method for all samples evaluated in this study was $22.98 \mathrm{~g} \mathrm{~kg}^{-1}$, close to those observed for Cerrado soils in other studies (Lopes and Cox, 1977; Siqueira Neto et al., 2009).

The results of the Mebius method were the closest $\left(R^{2}=0.87\right)$ to the results of the elemental analysis (Figure 2), justified by the external heating under reflux (Chatterjee et al., 2009; Gatto et al., 2009; Conyers et al., 2011) that potentialized the oxidation process. Rheinheimer et al. (2008) obtained a higher coefficient $\left(\mathrm{R}^{2}\right.$ $=0.97)$ of linear regression for the relation between the same methods, although a smaller number of samples were used of a more homogeneous origin, from two locations only. In any case, the high coefficient of regression between the two methods demonstrated that the Mebius method is reasonably effective in the recuperation of total SOC in relation to the reference method.

Table 1 - Carbon values obtained by the different methods of soil organic carbon analysis.

\begin{tabular}{lcccc}
\hline Method & Minimum & Maximum & Mean & Standard Deviation \\
\cline { 2 - 4 } & \multicolumn{3}{c}{$\mathrm{g} \mathrm{kg}^{-1}$} & \\
$\mathrm{C}_{\text {Elemental Analysis }}$ & 5.8 & 54.0 & 22.9 & $\mathrm{nd}$ \\
$\mathrm{OC}_{\text {Wakley and Black }}$ & 3.6 & 47.1 & 15.5 & \pm 0.6 \\
$\mathrm{OC}_{\text {Mebius }}$ & 4.6 & 50.9 & 17.7 & \pm 0.7 \\
$\mathrm{OC}_{\text {Colorimetric }}$ & 3.6 & 46.5 & 16.4 & \pm 1.1 \\
$\mathrm{OC}_{\text {Gravimetric }}$ & 6.15 & 126.31 & 51.19 & \pm 2.08 \\
\hline
\end{tabular}

The colorimetric method showed similar efficiency to the Walkley and Black, and can, therefore, be a viable alternative in routine laboratories, since it offers greater convenience in procedure and reproducibility, while reducing the use of toxic reagents. Furthermore, the colorimetric method showed positive correlation with the reference method $\left(\mathrm{R}^{2}=0.85\right)$. Other studies have demonstrated that it is possible to combine wet digestion methods with photometric determination (Conyers et al., 2011), permitting a simpler way of determining soil C instead of titration.

The method that had the lowest coefficient of linear regression with the reference method was the gravimetric method. The low $\mathrm{R}^{2}(0.66)$ can be attributed to the large variation in mass loss. In soils the mineral fraction is greater than the organic one and part of the mineral components are hygroscopic or contain structural water. It is, therefore, likely that these soil components lose water at high temperatures. This mass loss resulting from the volatilization of hygroscopic and structural water is accounted for along with the mass of organic compounds lost in the form of $\mathrm{CO}_{2}$, which implies overestimation of the organic component of the sample (Davies, 1974; Miyazawa et al., 2000; Melo et al., 2008).

Jankauskas et al. (2006) worked with only two soils and Pereira et al. (2006) used samples with high OC content. These authors found correlations of 0.80 and 0.94 , respectively, between the $\mathrm{C}$ obtained by the gravimetric method and elemental analysis. However, a wide range of soils of the Cerrado biome was used in our study. This characteristic could explain the lowest coefficient of linear regression obtained in our study.

In general, the methods based on wet digestion tended to underestimate the SOC level, as compared with the reference methods, while the gravimetric method overestimated it, which was also observed in other studies (Silva et al., 1999; Gatto et al., 2009; McCarty et al., 2011).

Only between 60 and $86 \%$ of the SOC is oxidized by the Walkley and Black method and an average correction factor of 1.32 is required to obtain the actual values of SOC (Walkley and Black, 1934). However, this recovery may vary depending on the soil properties such as clay content, mineralogy, aggregation and the quality of the soil organic matter. Thus, Conyers et al. (2011) suggested that the SOC determined by Walkley and Black should be considered as readily oxidisable carbon and no attempt to convert to total carbon should be taken due to the large variation in soil properties.

In the methods based on wet digestion, the oxidation of $\mathrm{C}$, with or without heating, is not complete, determining essentially only organic $\mathrm{C}$. The oxidation with potassium dichromate only promotes partial oxidation of the $\mathrm{C}$. The $\mathrm{C}$ in the organic fractions that are protected by the mineral fraction, the refractory $\mathrm{C}$ (e.g. charcoal) and inorganic $C$ (carbonates) are not fully attacked during the acid digestion (Nelson and Sommers, 1996). Thus, the methods based on wet oxidation, with 

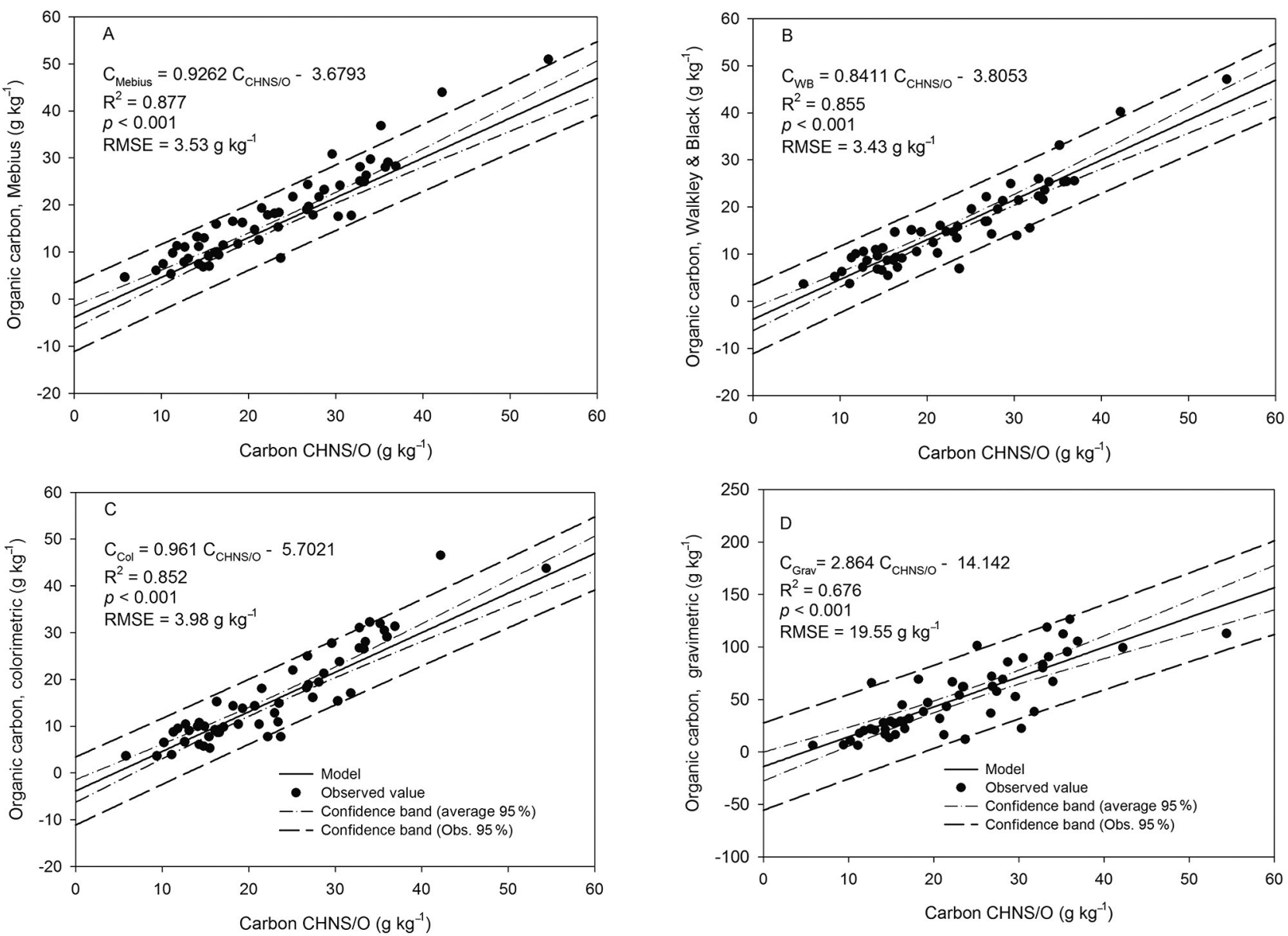

Figure 2 - Regressions between the carbon content of soils obtained by the reference method (Elemental Analysis) and by the comparative methods, A - Mebius, B - Walkley and Black, C - Colorimetric, D - Gravimetric.

external heating, can be reliable and efficient to determine SOC without overestimating due to the oxidation of the inorganic C (Nelson and Sommers, 1996; Conyers et al., 2011). However, wet oxidation methods utilize toxic compounds, such as $\mathrm{Cr}^{6+}$, that are potentially hazardous for human beings and generate toxic waste that needs safe disposal (Cohen et al., 1993).

Comparing the methods that are based on wet digestion the $\mathrm{C}$ levels obtained by the Mebius method were higher than the ones obtained by the Walkley and Black and Colorimetric methods. This confirms the efficiency of external heating during the digestion process, which maintains the temperature constant during the whole oxidation process. On average, the $\mathrm{C}$ determined by the Mebius method was $15 \%$ higher than that obtained by using the Walkley and Black. The difference found between the two methods by Nelson and Sommers (1996) was higher, $30 \%$ on average. This lower recovery of the Mebius method as compared with the Walkley and Black obtained in the case of the Brazilian savannah soils might be attributed to the type of the organic $\mathrm{C}$ in these soils, where much is stabilized in inert form as charcoal and protected in soil microaggregates. The $\mathrm{C}$ in the form of charcoal in the soils of the Cerrado can be as high as $40 \%$ (Jantalia et al., 2007). The binding of clay particles (kaolinite and aluminum and iron oxides and hydroxides together with organic matter) to form very resistant microaggregates in Oxisols is particularly pronounced (Cooper et al., 2005). External heating is not sufficient to fully oxidize these forms of $\mathrm{C}$.

\section{Soil use and the methods for SOC analysis}

Figure 3 presents the result of the principal component analysis (PCA) of the SOC values obtained by the methods classified by soil use. There were no groupings identified, indicating no relation between the analytical methods for SOC determination and soil use. Thus, the agricultural use of Cerrado soils do not interfere in the recovery of carbon obtained by the methods, even considering the use of lime to correct soil acidity.

The absence of a pattern for distinguishing between native and agricultural areas for methods of SOC determination in Cerrado soils (Figure 3 ) is also supported by the data presented in Table 2 . The type of land use 


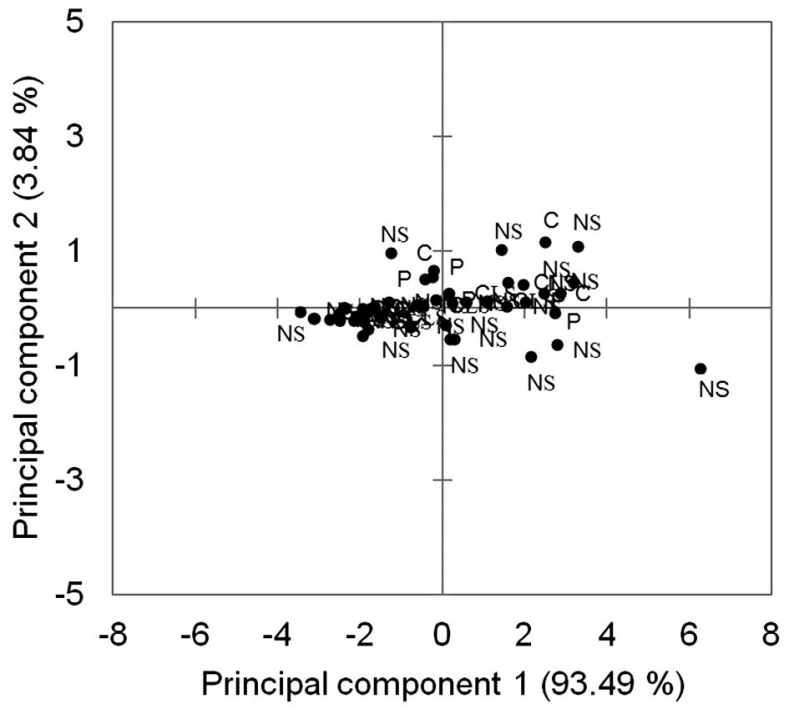

Figure 3 - Principal component analysis (PCA) of the organic carbon content obtained by different methods and classified by the type of land use. (NS - Native Savannah, C - Crop, P - Pasture, CLS Integrated Crop-Livestock System).

affects the accumulation of carbon in the soil (Carvalho et al., 2010) as well as its ability due to changes in its compartments (Figueiredo et al., 2010). However, even in soils under native vegetation, where there is large accumulation of inert carbon as charcoal, the interference of this stable carbon in the relationship between the methods of SOC analysis was not verified. The small differences in the $\mathrm{R}^{2}$ of the regressions between soils under native vegetation and under land use systems indicate that the relationships of the carbon determined by the different methods are maintained, regardless of land use in the Cerrado.

\section{Mineralogy and the methods of SOC analysis}

A positive relation between gibbsite and the $\mathrm{C}$ obtained by the gravimetric method was observed $\left(\mathrm{R}^{2}\right.$ $=0.90$ ) (Table 3 ). The $\mathrm{R}^{2}$ values obtained by regression between gibbsite and the $\mathrm{C}$ obtained by other methods were around 0.50 . These results demonstrate that the interference of the type of the clay mineral in the soil is variable and depends on the method of soil C analysis used. Davies (1974) found good agreement between organic matter contents as determined by Walkley and Black and the loss-on-ignition method except in those soils containing gibbsite (gibbsite losses were about $35 \%$ of structural water when heated to $300{ }^{\circ} \mathrm{C}$ ).

In highly weathered soils under tropical climate, which contain high amounts of kaolinite and hydrated aluminosilicates, such as gibbsite and goethite, the $\mathrm{C}$ content of the soil by this method is commonly overestimated (Melo et al., 2008). The intervals of dehydroxylation of gibbsite are usually between 200-300 ${ }^{\circ} \mathrm{C}$ (Martins, 2000; Sleutel et al., 2007) the same temperature
Table 2 - Relationships between methods of determining soil organic carbon.

\begin{tabular}{|c|c|c|c|c|}
\hline \multicolumn{2}{|c|}{ Method } & \multicolumn{3}{|c|}{ Parameters of the linear regression } \\
\hline$x$ & $y$ & $a$ & $b$ & $\mathrm{R}^{2}$ \\
\hline \multicolumn{5}{|c|}{ All soils } \\
\hline \multirow{4}{*}{ CHNS/O } & WB & -3.8053 & 0.8411 & $0.855^{*}$ \\
\hline & ME & -3.6793 & 0.9262 & $0.877^{*}$ \\
\hline & $\mathrm{COL}$ & -5.7021 & 0.9610 & $0.852^{*}$ \\
\hline & GRAV & -14.142 & 2.864 & $0.676^{*}$ \\
\hline \multirow{4}{*}{ WB } & CHNS/O & 7.1666 & 1.0171 & $0.855^{*}$ \\
\hline & ME & 0.7752 & 1.0841 & $0.994^{*}$ \\
\hline & $\mathrm{COL}$ & -0.9137 & 1.1139 & $0.947^{*}$ \\
\hline & GRAV & 0.1945 & 3.3156 & $0.749^{*}$ \\
\hline \multirow{4}{*}{ ME } & CHNS/O & 6.2808 & 0.9473 & $0.877^{*}$ \\
\hline & ME & -0.6177 & 0.9168 & $0.994^{*}$ \\
\hline & $\mathrm{COL}$ & -1.6498 & 1.0241 & $0.946^{*}$ \\
\hline & GRAV & -2.0230 & 3.0496 & $0.750^{*}$ \\
\hline \multirow{4}{*}{$\mathrm{COL}$} & CHNS/O & 8.4279 & 0.8867 & $0.852^{*}$ \\
\hline & WB & 1.5946 & 0.8499 & $0.947^{*}$ \\
\hline & ME & 2.4635 & 0.9239 & $0.946^{*}$ \\
\hline & GRAV & 4.6219 & 2.8711 & $0.737^{*}$ \\
\hline \multirow{4}{*}{ GRAV } & CHNS/O & 10.717 & 0.2362 & $0.676^{*}$ \\
\hline & WB & 3.8038 & 0.2261 & $0.750^{*}$ \\
\hline & ME & 4.8587 & 0.2459 & $0.750^{*}$ \\
\hline & $\mathrm{COL}$ & 3.081 & 0.2566 & $0.737^{*}$ \\
\hline \multicolumn{5}{|c|}{ Soils under native savannah vegetation } \\
\hline \multirow{4}{*}{ CHNS/O } & WB & -4.5218 & 0.8719 & $0.852^{*}$ \\
\hline & ME & -4.4591 & 0.9605 & $0.877^{*}$ \\
\hline & $\mathrm{COL}$ & -4.8029 & 0.9749 & $0.852^{*}$ \\
\hline & GRAV & -11.657 & 2.6407 & $0.640^{*}$ \\
\hline \multicolumn{5}{|c|}{ Soils under agricultural use } \\
\hline \multirow{4}{*}{ CHNS/O } & WB & -1.897 & 0.7535 & $0.870^{*}$ \\
\hline & ME & -1.5569 & 0.8276 & $0.884^{*}$ \\
\hline & $\mathrm{COL}$ & -6.8281 & 0.9749 & $0.838^{*}$ \\
\hline & GRAV & -29.386 & 3.975 & $0.831^{*}$ \\
\hline
\end{tabular}

CHNS / O Elemental Analysis; WB, Walkley and Black; ME, Mebius; COL, Colorimetric; GRAV, Gravimetric; *model is significant according to the $\mathrm{F}$ test $(p<0.05)$.

range used in this study. Figure 4 shows the relation of the $\mathrm{C}$ values obtained by the gravimetric method and the gibbsite content of the soil samples under study. The $\mathrm{R}^{2}$ $=0.90$ justifies the overestimation of the $\mathrm{C}$ by the gravimetric method, showing that the mass loss attributed to the combustion of SOC might include mass loss due to the dehydroxylation of gibbsite.

The relationship between goethite and the $\mathrm{C}$ measured by the methods followed the same relationship that had been found for gibbsite; however, the $\mathrm{R}^{2}$ for the gravimetric method was less than 0.65 . The kaolinite had low regression coefficients with the $\mathrm{C}$ obtained by the methods, demonstrating that this clay mineral had little interference in the determination of $\mathrm{C}$. The gravimetric method had the lowest linear regression coefficient in relation to the kaolinite, which can be explained by the use of a temperature that did not result in mass loss of this clay mineral during calcination. 
Table 3 - Relationship between clay mineral type and soil carbon determined by different methods.

\begin{tabular}{|c|c|c|c|c|}
\hline \multirow{2}{*}{$\frac{\text { Clay mineral }}{x}$} & \multirow{2}{*}{$\frac{\text { Method }}{y}$} & \multicolumn{3}{|c|}{ Parameters of the linear regression } \\
\hline & & a & $b$ & $\mathrm{R}^{2}$ \\
\hline \multirow{5}{*}{ GIB } & CHNS/O & 12.883 & 0.4896 & $0.516^{*}$ \\
\hline & WB & 6.9372 & 0.5103 & $0.556^{*}$ \\
\hline & ME & 5.7303 & 0.4682 & $0.553^{*}$ \\
\hline & $\mathrm{COL}$ & 5.2349 & 0.5329 & $0.546^{*}$ \\
\hline & GRAV & 4.6572 & 2.2597 & $0.894^{*}$ \\
\hline \multirow{5}{*}{ GOE } & CHNS/O & 4.2899 & 0.8020 & $0.586^{*}$ \\
\hline & WB & -0.9391 & 0.7864 & $0.551^{*}$ \\
\hline & ME & -1.5657 & 0.7249 & $0.554^{*}$ \\
\hline & $\mathrm{COL}$ & -4.1614 & 0.8718 & $0.612^{*}$ \\
\hline & GRAV & -17.804 & 2.9665 & $0.647^{*}$ \\
\hline \multirow{5}{*}{ CAU } & CHNS/O & 9.5306 & 0.3036 & $0.165^{*}$ \\
\hline & WB & 4.1701 & 0.3036 & $0.156^{*}$ \\
\hline & ME & 3.4876 & 0.2675 & $0.149^{*}$ \\
\hline & $\mathrm{COL}$ & 3.8573 & 0.2794 & $0.124^{*}$ \\
\hline & GRAV & 23.172 & 0.6519 & $0.062^{*}$ \\
\hline \multirow{5}{*}{ Clay } & CHNS/O & 11.342 & 0.2440 & $0.251^{*}$ \\
\hline & WB & 3.1037 & 0.2613 & $0.347^{*}$ \\
\hline & $\mathrm{ME}$ & 4.0282 & 0.2856 & 0.351 * \\
\hline & $\mathrm{COL}$ & 2.5353 & 0.2912 & 0.329 * \\
\hline & GRAV & -9.5359 & 1.2927 & $0.580^{*}$ \\
\hline
\end{tabular}

CHNS / 0 Elemental Analysis; WB, Walkley and Black; ME, Mebius; COL, Colorimetric; GRAV, Gravimetric, GIB, Gibbsite; GOE, Goethite; CAU, Kaolinite; * model is significant according to the $\mathrm{F}$ test $(p<0.05)$.

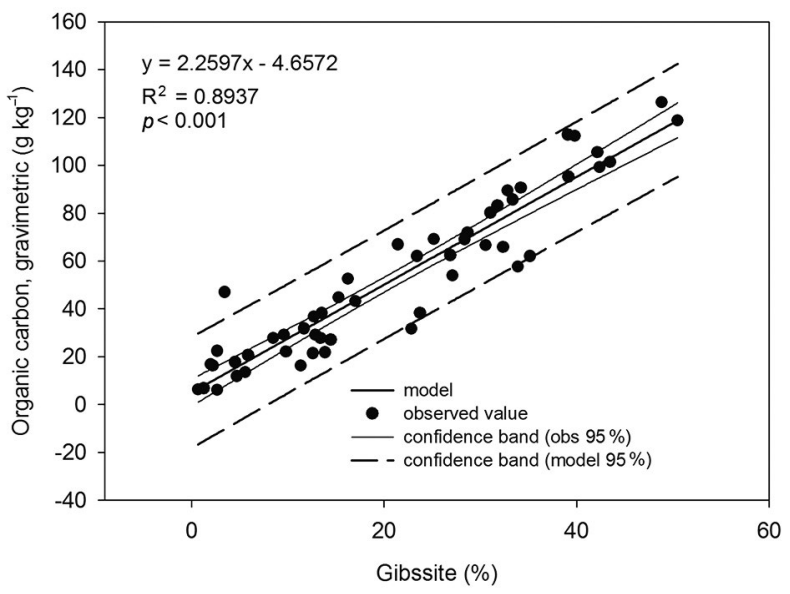

Figure 4 - Relationship between the carbon quantified by the gravimetric method and gibbsite content in 54 Cerrado soils ( $p$ $=0.95)$.

The average levels of kaolinite and gibbsite of the Oxisols of this study, obtained by thermogravimetric analysis, were $467.0 \mathrm{~g} \mathrm{~kg}^{-1}$ and $205.4 \mathrm{~g} \mathrm{~kg}^{-1}$, respectively, being in agreement with values obtained by other authors (Gomes et al., 2004; Vendrame et al., 2011). Ninety percent $(90 \%)$ of the soils had higher levels of kaolinite than gibbsite which suggests that caution has to be taken in generalizing about the richness of the Cerrado soils in gibbsite and classifying these soils as oxidic.
Clay content and the methods of SOC analysis

There was a positive relationship between the clay content and the $\mathrm{C}$ obtained by the different methods (Table 3). However, the $\mathrm{R}^{2}$ values were lower compared with the results presented by Zinn et al. (2007) for Cerrado soils (Zinn et al., 2007). Soil texture greatly influences the retention of organic matter through the formation of organo-mineral complexes favored by humified compounds. In our study, the values of the regression coefficients did not exceed 0.58. This lower value of the regression coefficients can be attributed to the large variability of soils used in the present study, representing different soil types and large spatial distribution of the soil samples.

\section{Conclusions}

Wide variation in the soil carbon content obtained by different methods was observed. The carbon content determined by the Mebius method produced the closest values to the reference method (elemental analysis), demonstrating greater recuperation of carbon than the other methods based on wet oxidation. The Walkley and Black and the colorimetric methods featured similar efficiency in determining soil $\mathrm{C}$. The colorimetric method, that generates smaller volume of toxic waste, has great potential to substitute the Walkley and Black method, which in Brazil is still widely used in routine soil analysis. The mineralogy of the soil, with an emphasis on gibbsite, showed influence in determining carbon by the gravimetric method. For the other methods gibbsite showed no interference in the quantification of organic carbon.

\section{References}

Carmo, D.L.; Silva, C.A. 2012. Quantification methods of carbon and organic matter in organic residues. Revista Brasileira de Ciência do Solo 36: 1211-1220 (in Portuguese, with abstract in English).

Carvalho, J.L.N.; Avanzi, J.C.; Silva, M.L.N.; Mello, C.R.; Cerri, C.E.P. 2010. Quantification methods of carbon and organic matter in organic residues. Revista Brasileira de Ciência do Solo 34: 277-289 (in Portuguese, with abstract in English).

Chatterjee, A.; Lal, R.; Wielopolski, L.; Martin, M.Z.; Ebinger, M.H. 2009. Evaluation of different soil carbon determination methods. Critical Reviews in Plant Science 28: 164-178.

Cohen, M.D.; Kargacin, B.; Klein, C.B.; Costa, M. 1993. Mechanisms of chromium carcinogenicity and toxicity. Critical Reviews in Toxicology 23: 255-281.

Conyers, M.K.; Poile, G.J.; Oaetes, A.A.; Waters, D.; Chan, K.Y. 2011. Comparison of three carbon determination methods on naturally occurring substrates and the implication for the quantification of 'soil carbon'. Soil Research 49: 27-33.

Cooper, M.; Vidal-Torrado, P.; Chaplot, V. 2005. Origin of microaggregates in soils with ferralic horizons. Scientia Agricola 62: 256-263.

Davies, B.E. 1974. Loss-on-ignition as an estimate of organic matter. Soil Science Society of America Journal 38: 150-151. 
Figueiredo, C.C.; Resck, D.V.S.; Carneiro, M.A.C. 2010. Labile and stable fractions of soil organic matter under management systems and native Cerrado. Revista Brasileira de Ciência do Solo 34: 907-916.

Gatto, A.; Barros, N.F.; Novais, R.F.; Silva, I.R.; Mendonça, E.S.; Villani, E.M.A. 2009. Comparison of methods for determination of organic carbon in soils under eucalypt plantations. Revista Brasileira de Ciência do Solo 33: 735-740 (in Portuguese, with abstract in English).

Gomes, J.B.C.; Curi, N.; Motta, P.E.F.; Ker, J.; Marques, J.J.G.S.M.; Schulze, D.G. 2004. Principal component analysis of physical, chemical, and mineralogical attributes of the Cerrado biome soils. Revista Brasileira de Ciência do Solo 28: 137-153 (in Portuguese, with abstract in English).

Jankauskas, B.; Slepetiene, A.; Jankauskiene, G.; Fullen, M.A.; Booth, C.A.A. 2006. A comparative study of Analytical methodologies to determine the soil organic matter content of Lithuanian Eutric Albeluvisols. Geoderma 136: 763-773.

Jantalia, C.P.; Resck, D.V.S.; Alves, B.R.J.; Zotarelli, L.; Urquiaga, S.; Boddey, R.M. 2007. Tillage effect on C stocks of a clayey Oxisol under a soybean-based crop rotation in the Brazilian Cerrado region. Soil and Tillage Research 95: 97-109.

Lopes, A.S.; Cox, F.R. 1977. A survey of the fertility status of surface soil under "Cerrado" vegetation in Brazil. Soil Science Society of America Journal 41: 742-747.

Martins, E.S. 2000. Integrated Method of Mineralogical Characterization of Deeply Weathered Soils. Embrapa Cerrados, Planaltina, DF, Brazil. (Comunicado Técnico, 37) (in Portuguese, with abstract in English).

McCarty, G.W.; Reeves III, J.B.; Yost, R.; Doraiswamy, P.C.; Doumbia, M. 2010. Evaluation of methods for measuring soil organic carbon in West African soils. African Journal of Agricultural Research 5: 2169-2177.

Mebius, L.J. 1960. A rapid method for the determination of organic carbon in soil. Analytica Chimica Acta 22: 120-124.

Melo, L.C.A.; Silva, C.A.; Dias, B.O. 2008. Characterization of the organic matrix of residues from different origins. Revista Brasileira de Ciência do Solo 32: 101-110 (in Portuguese, with abstract in English).

Miyazawa, M.; Pavan, M.A.; Oliveira, E.L.; Ionashiro, M.; Silva, A.K. 2000. Gravimetric determination of soil organic matter. Brazilian Archives of Biology and Technology 43: 475-478.

Nelson, D.W.; Sommers, L.E. 1996. Total carbon, organic carbon, and organic matter. p. 961-1010. In: Black, C.A., ed. Methods of soil analysis. Part 3. Chemical methods. Soil Science of America and American Society of Agronomy, Madison, WI, USA.

Pereira, M.G.; Valladares, G.S.; Anjos, L.H.C.; Benites, V.M.; Espíndula, J.R.A.; Ebeling, A.G. 2006. Organic carbon determination in histosols and soil horizons with high organic matter content from Brazil. Scientia Agricola 63: 187-193.
Pimentel, L.C.F.; Chaves, C.R.; Freire, L.A.A.; Afonso, J.C. 2006. The incredible use of dangerous chemicals in the past. Química Nova 29: 1138-1149 (in Portuguese, with abstract in English).

Resck, D.V.S.; Ferreira, E.A.B.; Figueiredo, C.C.; Zinn, Y.L. 2008. Organic matter dynamics in the Cerrado = Dinâmica da matéria orgânica no Cerrado. p. 359-417. In: Santos, G.A.; Silva, L.S.; Canellas, L.P.; Camargo, F.A.O., eds. Fundamentals of soil organic matter: tropical and subtropical ecosystems = Fundamentos da matéria orgânica do solo: ecossistemas tropicais e subtropicais. Metrópole, Porto Alegre, RS, Brazil (in Portuguese).

Rheinheimer, D.S.; Campos, B.H.C.; Giacomini, S.J.; Conceição, P.C.; Bortoluzzi, E.C. 2008. Comparison of determination methods of total organic carbon in soils. Revista Brasileira de Ciência do Solo 32: 435-440 (in Portuguese, with abstract in English).

Segnini, A.; Santos, L.M.; Silva, W.T.L.; Martin Neto, L.; Borato, C.; Melo, W.J.; Bolonhezi, D. 2008. Comparative study of carbon quantification methods in soil with high $\mathrm{Fe}$ contents (Oxisols). Química Nova 31: 94-97 (in Portuguese, with abstract in English).

Sheldrick, B.H.; Wang, C. 1993. Particle size distribution. p. 499511. In: Carter, M.R., ed. Soil sampling and methods of analysis. Canadian Society of Soil Science, Ann Arbor, MI, USA.

Silva, A.C.; Vidal-Torrado, P.; Abreu Junior, J. 1999. Methods of quantification of the organic matter of the soil. Revista Unifenas Alfenas 5: 21-26 (in Portuguese, with abstract in English).

Siqueira Neto, M.; Piccolo, M.C.; Scopel, E.; Costa Junior, C.; Cerri, C.; Bernoux, M. 2009. Total soil carbon and chemical attributes under different land uses in the Brazilian savanna. Acta Scientiarum Agronomy 31: $709-717$ (in Portuguese, with abstract in English).

Sleutel, S.; Neve, S.; Singier, B.; Hofman, G. 2007. Quantification of organic carbon in soils: a comparison of methodologies and assessment of the carbon content of organic matter. Communications in Soil Science and Plant Analysis 38: 26472657.

Vendrame, P.R.S.; Eberhardt, D.N.; Brito, O.R.; Marchão, R.L.; Quantin, C.; Becquer, T. 2011. Iron and aluminum forms and their relationship with texture, mineralogy and organic carbon in the Cerrado Oxisol. Semina: Ciências Agrárias 32: 1657-1666 (in Portuguese, with abstract in English).

Walkley, A.; Black, I.A. 1934. An examination of Degtjareff method for determining soil organic matter, and proposed modification of the chromic acid tritation method. Soil Science 37: 29-38.

Zinn, Y.L.; Lal, R.; Bigham, J.M.; Resck, D.V.S. 2007. Edaphic controls on soil organic carbon retention in the Brazilian Cerrado: soil texture and mineralogy. Soil Science Society of America Journal 71: 1204-1214. 